\title{
Thermal Rearrangements of Polybutadienes with Different Vinyl Contents*
}

\author{
MORTON A. GOLUB, Ames Research Center, National Aeronautics and \\ Space Administration, Moffett Field, California 94035
}

\section{Synopsis}

A study was made of the loss of double bonds in equibinary $(1,4-1,2)$ polybutadiene (EB) and in polybutadienes with $30 \% 1,2,70 \% 1,4$ (FI), and 10\% 1,2, 90\% 1,4 (DI) double-bond content, when heated in vacuum under nonpyrolytic conditions (temperature range $220-280^{\circ} \mathrm{C}$ ). These polymers were found to undergo second-order loss of 1,2 unsaturation with similar activation energies $\left(E_{a}\right.$ $=34.0 \pm 3 \mathrm{kcal} / \mathrm{mole}$ ), by analogy to the previously reported thermally induced loss of double bonds in 1,2-polybutadiene (VB) $\left(E_{a}=33.6 \pm 3 \mathrm{kcal} / \mathrm{mole}\right)$. Moreover, $\mathrm{EB}$ and FI exhibited also second-order loss of 1,4 unsaturation, with $E_{a} \mathrm{ca} .36$ and $40 \mathrm{kcal} / \mathrm{mole}$, respectively, while DI showed negligible loss of 1,4 unsaturation below $260^{\circ} \mathrm{C}$, in common with cis-1,4-polybutadiene (CB) (with $2 \% 1,2$ double bonds) examined earlier. The loss of 1,2 double bonds in the various polybutadienes with different vinyl contents is accompanied by substantial methyl production, ranging from about one methyl group formed for every 4-5 vinyl units lost in VB, to one methyl for every two vinyls lost in EB, and to almost one methyl for each vinyl lost in DI or CB. Mechanisms are proposed for the thermally induced loss of 1,2 and 1,4 unsaturation in various polybutadienes and for the accompanying methyl production.

\section{INTRODUCTION}

In several articles ${ }^{1-4}$ evidence was presented for a facile $[2+2]$ cycloaddition of double bonds in certain polymers having a 1,6-diene structure when heated under nonpyrolytic conditions in the absence of oxygen. This so-called type II cyclization was invoked for 1,2-polybutadiene (VB), ${ }^{1} 3,4$-polyisoprene (VI), ${ }^{1}$ polypentenamer $(\mathrm{PP}),{ }^{2}$ equibinary $(1,4-1,2)$ polybutadiene (EB) ${ }^{3}$ and equibinary $(3,4-1,4)$ polyisoprene $(\mathrm{EI}){ }^{3}$ The cycloaddition is exemplified by the formation of bicycloheptane structures in VB or VI from pairs of 1,2 or 3,4 double bonds:

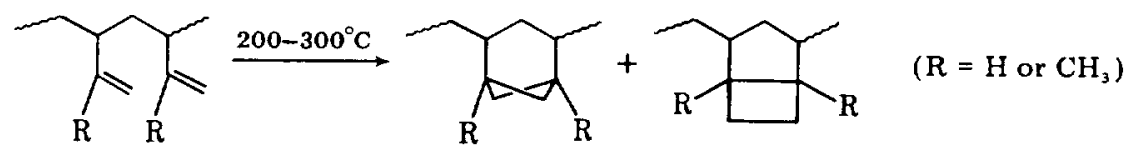

For EB (or EI), the thermally induced loss of unsaturation is pictured as involving cycloaddition of both 1,2-1,2 (or 3,4-3,4) dyads [reaction (1)] and of 1,2-1,4 (or $3,4-1,4)$ dyads [reaction (2)].

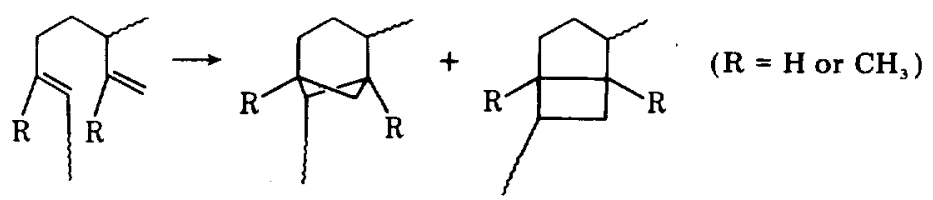

\footnotetext{
* Presented at the Division of Polymer Chemistry at the Second Chemical Congress of the North American Continent, Las Vegas, Nevada, August 24-29, 1980.

Journal of Polymer Science: Polymer Chemistry Edition, Vol. 19, 1073-1083 (1981)

Published by John Wiley. \& Sons, Inc.

Article not subject to U.S. Copyright.

$\operatorname{CCC} 0360-6376 / 81 / 051073-11 \$ 01.10$
} 
In addition to reactions (1) and (2), $-\mathrm{CH}=\mathrm{CH}-$ units in $\mathrm{EB}$ or $\mathrm{PP}$ also undergo thermal cis-trans isomerization ${ }^{2,3}$ in common with cis-1,4-polybutadiene (CB). ${ }^{4}$ Analogous cycloaddition and isomerization processes have also been indicated for the photorearrangements of the above polymers with pendant double bonds. ${ }^{3}$

Whereas cycloaddition appears to be the dominant route for loss of 1,2 double bonds in VB, and for loss of 1,2 and 1,4 double bonds in EB, a rather different process was proposed by Grassie and Heaney ${ }^{5}$ to account for the thermal anaerobic consumption of 1,2 double bonds-but not 1,4 double bonds-in a high-1,4 polybutadiene (PBD) under nonpyrolytic conditions:
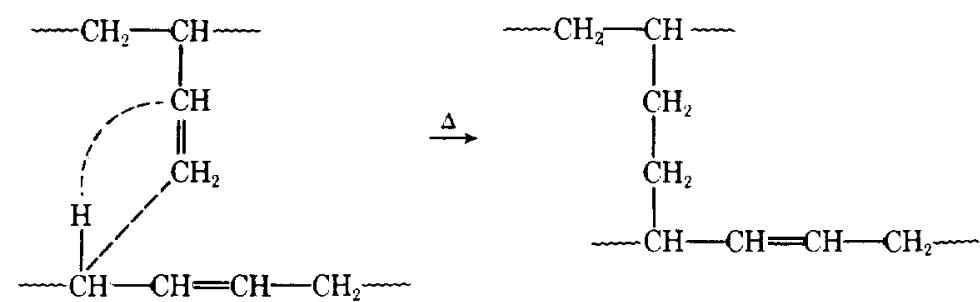

This process accounts also for the crosslinking associated with the loss of 1,2 double bonds in the heated PBD. The isolated vinyl groups in PBD were reported to disappear by a nonradical first-order process with an activation energy $E_{a}$ of $15 \mathrm{kcal} / \mathrm{mole}^{5}$; by contrast, the vinyl groups in VB disappear by a secondorder process with $E_{a}=33.6 \pm 3 \mathrm{kcal} / \mathrm{mole} .^{1}$ Because of the relatively low vinyl content in PBD (ca. 9-14\% 1,2), Grassie and Heaney viewed the reaction of pairs of 1,2 double bonds in that polymer as unlikely. This also reported that there was no thermally induced loss of 1,4 double bonds in $\mathrm{PBD},{ }^{5}$ a result which is in accord with that of $\mathrm{CB}^{2,4}$ (with ca. $2 \% 1,2$ ) at temperatures below $275^{\circ} \mathrm{C}$, but which is in conflict with the situation in $\mathrm{EB}^{3}(48 \% 1,2)$, where significant loss of 1,4 double bonds is indicated. The aim of this article is several fold: to resolve conflicts concerning order and activation energy for loss of 1,2 double bonds in PBD and VB, and concerning loss of 1,4 double bonds in EB and PBD; to reassess the Grassie-Heaney reaction (3); and to obtain new insight into methyl production during thermal cyclization of $\mathrm{VB}^{1,4}$ and $\mathrm{EB} .^{3}$

\section{EXPERIMENTAL}

Purified samples of $\mathrm{CB}^{6}$ and $\mathrm{EB}^{3}$ were similar to those used previously. Two additional polybutadienes, DI ("Diene-35-NF") and FI (an experimental sample), with 10 and $30 \% 1,2$ content, respectively, were obtained from Halasa and Hall, Firestone Tire \& Rubber Co., Akron, $\mathrm{OH}$, and purified as described. ${ }^{3}$ Thin films of these polymers cast onto $\mathrm{NaCl}$ disks were heated isothermally in vacuum at different temperatures and examined by infrared (IR) spectroscopy with a Perkin-Elmer model 180 spectrophotometer. The residual vinyl unsaturation $U_{1,2}$ was calculated by means of the absorbance expression, $U_{1,2}=\left(A_{11.1}\right)$ $\left.A_{6.9}\right)_{h} /\left(A_{11.1} / A_{6.9}\right)_{0}$, where the $11.1-\mu \mathrm{m}$ band is associated with $-\mathrm{CH}=\mathrm{CH}_{2}$, the $6.9-\mu \mathrm{m}$ band is an internal standard, and the subscripts $h$ and 0 refer to the heated and unheated films, respectively. The growth of methyl was followed by the absorbance ratio $A_{7.3} / A_{6.9} \equiv A^{\prime}$. The residual 1,4 unsaturation $U_{1,4}$ was 


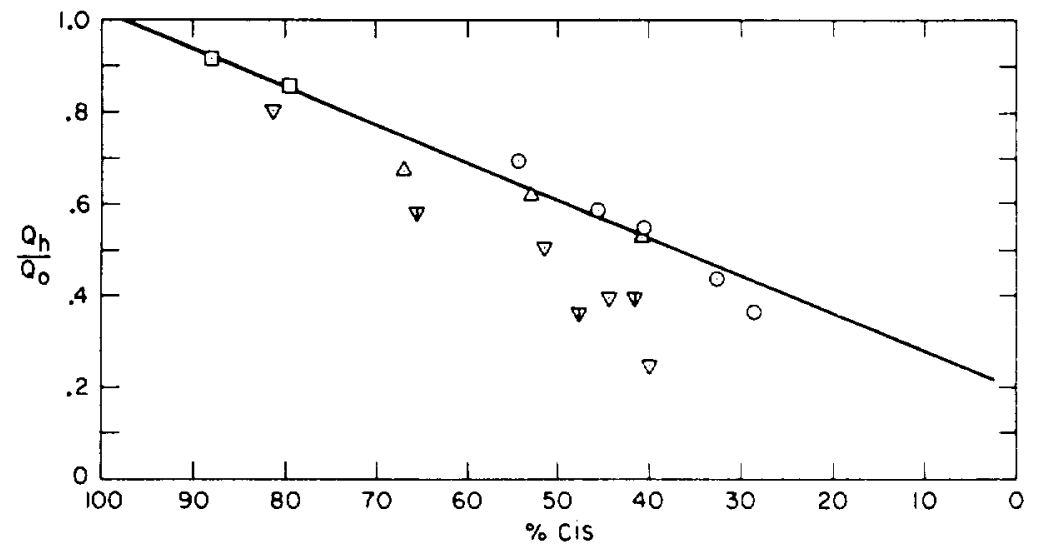

Fig. 1. Relative change in thickness-normalized $Q$ parameter accompanying thermal isomerization in $\mathrm{CB}$ film at various temperatures. The straight line represents corresponding change in the $Q$ parameter for $\mathrm{CB}$ samples subjected to photosensitized isomerization, and is designated as $Q^{\prime}$ in the text. (ㅁ) $213^{\circ} \mathrm{C},(\Delta) 236^{\circ} \mathrm{C},(\mathrm{O}) 249^{\circ} \mathrm{C},(\nabla) 275^{\circ} \mathrm{C},(\nabla) 299^{\circ} \mathrm{C}$.

determined in a manner similar to that of a previous article ${ }^{2}$ : first, the percent cis double bonds $C$ was calculated as $100\left[x A_{c} /\left(x A_{c}+A_{t}\right)\right]$, where $A_{c}$ and $A_{t}$ are the absorbances of the cis and trans peaks at 13.9 and $10.4 \mu \mathrm{m}$, respectively, and $x$ is the ratio of extinction coefficients, $\epsilon_{t} / \epsilon_{c}=4.4$. Next, the absorbance pa-

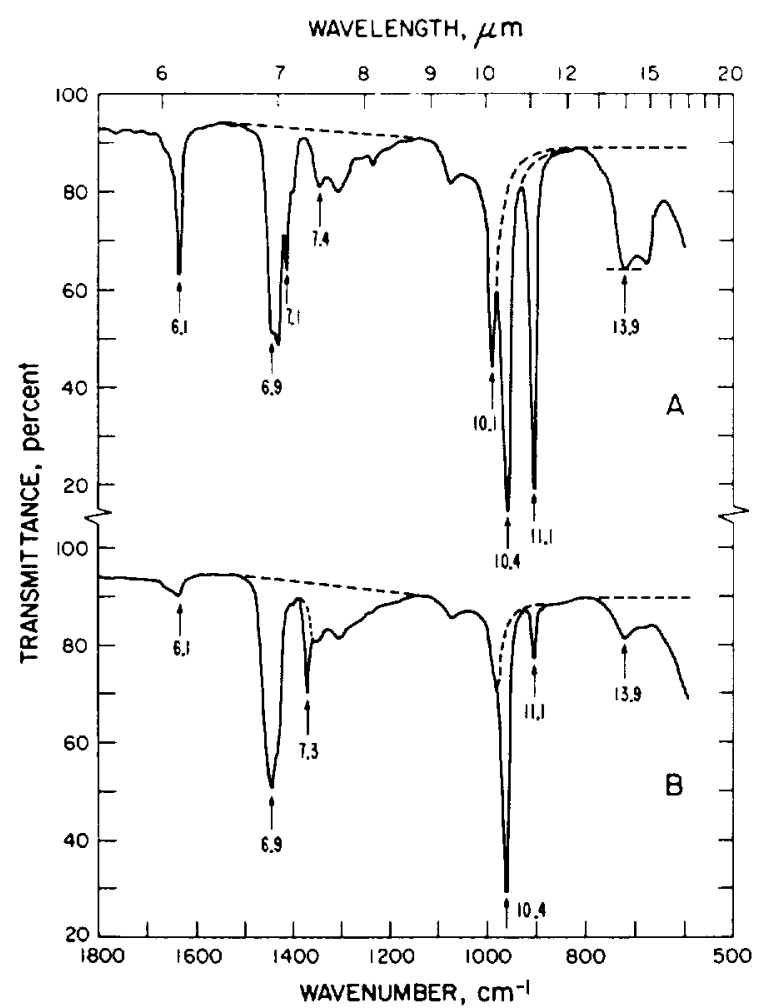

Fig. 2. IR spectra of FI film (A) before and (B) after heating at $260^{\circ} \mathrm{C}$ for $28 \mathrm{hr}$ in vacuum. 


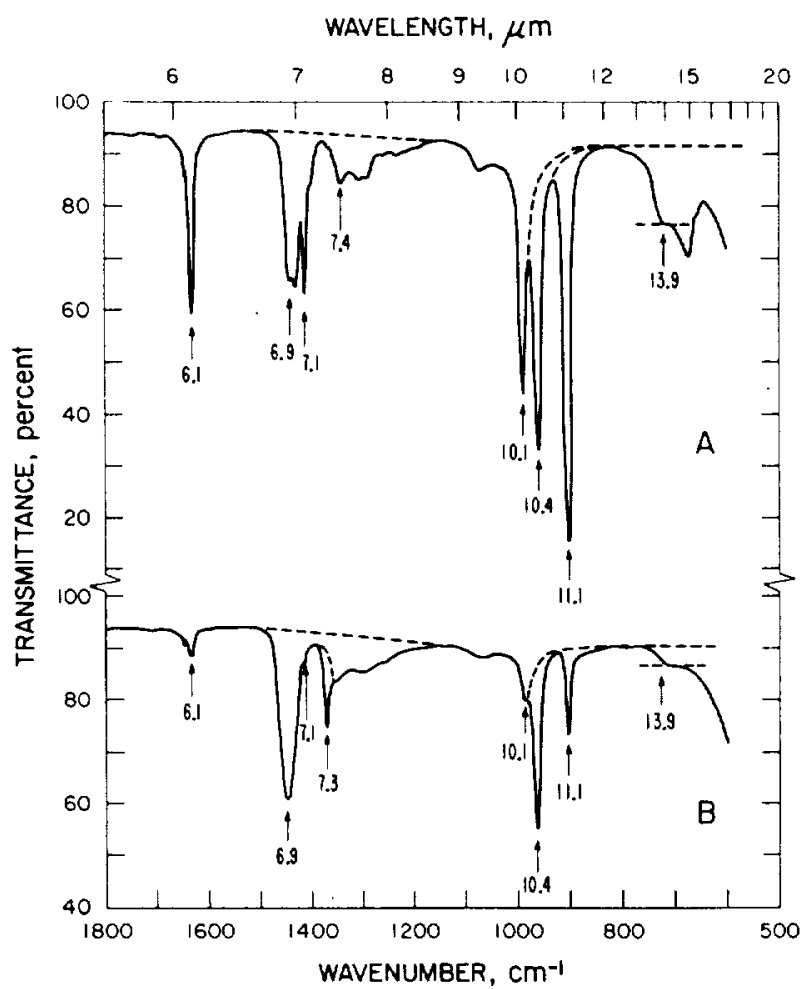

Fig. 3. IR spectra of EB film (A) before and (B) after heating at $260^{\circ} \mathrm{C}$ for $28 \mathrm{hr}$ in vacuum.

rameter $Q \equiv\left(x A_{c}+A_{t}\right) / A_{6.9}$ was determined for each film, before and after heating, and a thickness-normalized quantity $Q_{h} / Q_{0}$ was calculated. Since $Q_{h} / Q_{0}$ was known to depend on cis content, ${ }^{2}$ this quantity could not be used directly to characterize residual 1,4 unsaturation; instead, the latter was obtained by dividing each $Q_{h} / Q_{0}$ value by the corresponding $Q_{h}^{\prime} / Q_{0}^{\prime}$, where $Q^{\prime}=0.0083 C$ +0.19 . The $Q^{\prime}$ expression, which corresponds to the straight-line plot in Figure 1 , was obtained by photosensitized isomerization of $\mathrm{CB}$ which involves no loss of 1,4 unsaturation. ${ }^{2}$ As noted above, departure from the straight line of Figure 1 , the analog of Figure 5, ref. 2, is significant only for CB films heated above ca. $275^{\circ} \mathrm{C}$.

\section{RESULTS AND DISCUSSION}

As shown in Figure 2, FI undergoes thermally induced loss of both 1,2 and 1,4 unsaturation, indicated by decreases in the 11.1-, 10.1-, 7.1-, and $6.1-\mu \mathrm{m}$ absorptions (all associated with $-\mathrm{CH}=\mathrm{CH}_{2}$ ), and by decreases of both 13.9 - and 10.4- $\mu \mathrm{m}$ absorptions (cis and trans $-\mathrm{CH}=\mathrm{CH}-$, respectively) which also reflect cis-trans isomerization. The growth of the 7.3- $\mu \mathrm{m}$ absorption indicates formation of methyl groups. The dashed lines in Figure 2 denote backgrounds used to measure absorbances of the relevant bands. The unsaturation of FI was changed from $30.0 \% 1,2,31.5 \%$ cis $-1,4$, and $38.5 \%$ trans- 1,4 initially to $2.6 \% 1,2$, $12.4 \%$ cis $-1,4$, and $30.2 \%$ trans $-1,4$ double bonds after $28 \mathrm{hr}$ at $260^{\circ} \mathrm{C}$. The 


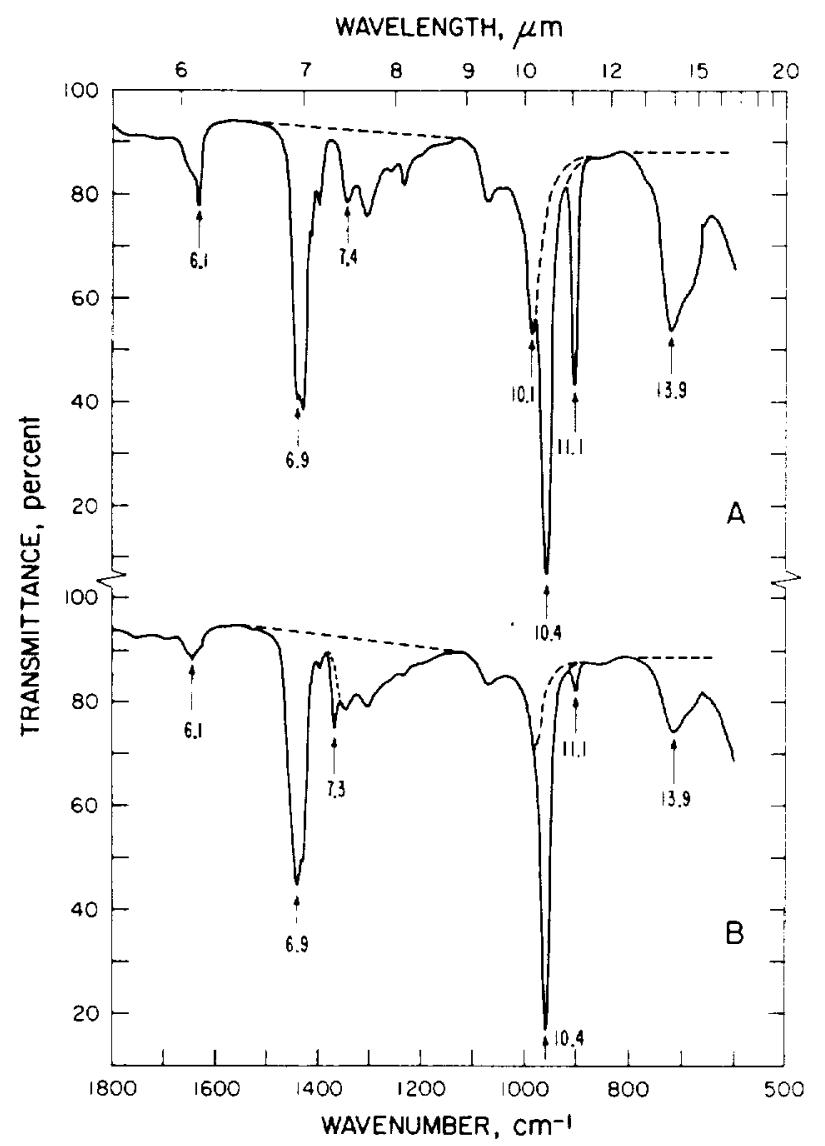

Fig. 4. IR spectra of DI film (A) before and (B) after heating at $260^{\circ} \mathrm{C}$ for $28 \mathrm{hr}$ in vacuum.

changes noted for FI are qualitatively the same as those found previously for $\mathrm{EB},{ }^{3}$ even though their initial 1,2 contents ( 30 and $48 \%$, respectively) are different. To facilitate comparison, new IR spectra of EB film before and after heating at $260^{\circ} \mathrm{C}$ for $28 \mathrm{hr}$ are presented in Figure 3: from an initial unsaturation of $48 \%$ $1,2,21 \%$ cis-1,4, and $31 \%$ trans-1,4, EB was thermally rearranged to a structure with ca. $5 \% 1,2,6 \%$ cis-1,4, and $16 \%$ trans-1,4 double bonds, accompanied by methyl production.

As may be seen in Figure 4, DI likewise undergoes thermally induced loss of 1,2 unsaturation, cis-trans isomerization, and methyl formation, together with some loss of 1,4 unsaturation. From an initial unsaturation of $10.0 \% 1,2,43.2 \%$ cis-1,4, and $46.8 \%$ trans $-1,4$, DI was converted to a structure with $1.0 \% 1,2,22.3 \%$ cis- 1,4 , and $46.0 \%$ trans $-1,4$ after $28 \mathrm{hr}$ at $260^{\circ} \mathrm{C}$. The loss of 1,4 unsaturation in DI, while significant at $260^{\circ} \mathrm{C}$, was very slow at $250^{\circ} \mathrm{C}$ and negligible at lower temperatures. This is at variance with the findings of Grassie and Heaney on $\mathrm{PBD}^{5}$ which, although having a vinyl content similar to that of $\mathrm{DI}$, showed no loss of 1,4 unsaturation at temperatures up to $260^{\circ} \mathrm{C}$. A possible explanation for this discrepancy at $260^{\circ} \mathrm{C}$ is the fact that in the cited work ${ }^{5}$ the $10.3-\mu \mathrm{m}$ trans band was used nonjudiciously as an internal standard; the intensity of that band, of course, would be affected by cis-trans isomerization. 


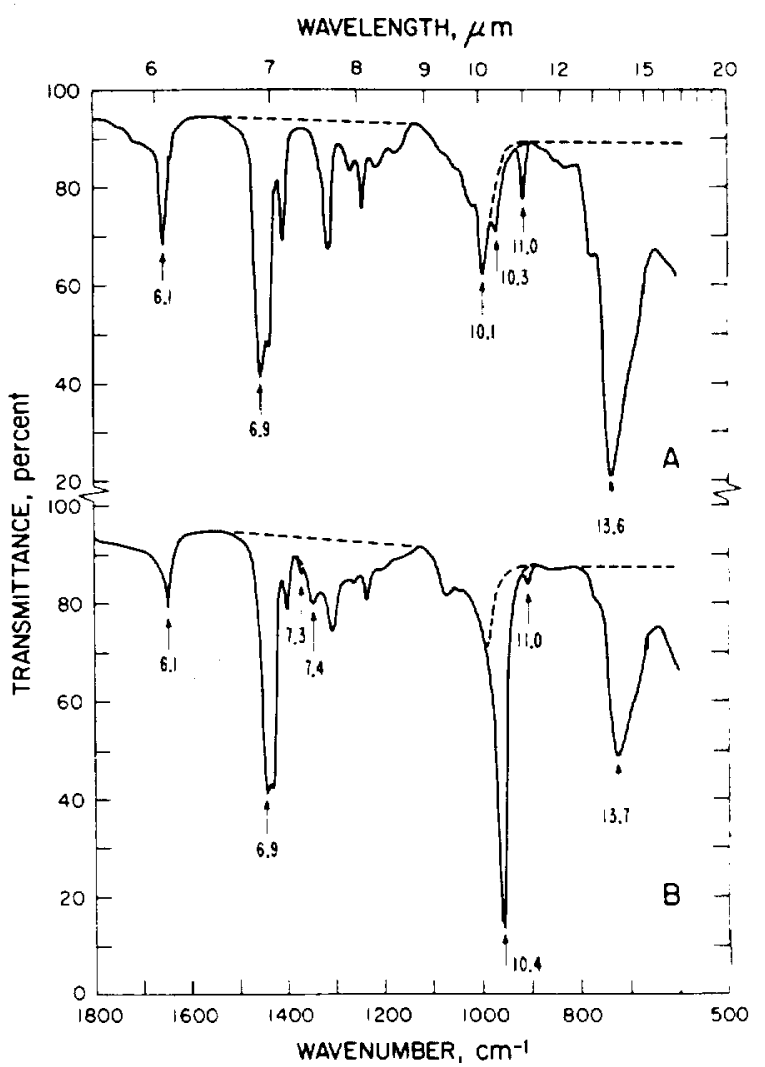

Fig. 5. IR spectra of CB film (A) before and (B) after heating at $230^{\circ} \mathrm{C}$ for $67 \mathrm{hr}$ in vacuum.

The IR spectra of thermally isomerized CB were described previously ${ }^{2}$ but not actually shown. For purposes of completeness, it is useful to include Figure 5 which shows that, accompanying the cis-trans isomerization (indicated by diminution of the $13.6-13.7-\mu \mathrm{m}$ band and growth of the $10.3-10.4-\mu \mathrm{m}$ band), some 1,2 double bonds are lost (decrease of the $11.0-\mu \mathrm{m}$ band), and some methyl groups are formed (appearance of the weak peak at $7.3 \mu \mathrm{m}$; the $7.4-\mu \mathrm{m}$ peak in Fig. 5, and in the other IR spectra is associated with trans $-\mathrm{CH}=\mathrm{CH}-$ units). The unsaturation of $\mathrm{CB}$ was thus changed from ca. $96.0 \%$ cis $-1,4,2.0 \%$ trans $-1,4$, and $2.0 \% 1,2$ initially to ca. $56.7 \%$ cis- $1,4,41.3 \%$ trans- 1,4 , and $0.6 \% 1,2$ unsaturation after $67 \mathrm{hr}$ at $230^{\circ} \mathrm{C}$. Prolonged heating of $\mathrm{CB}$ results in an equilibrium cis content of ca. $35 \%$ of the 1,4 double bonds. ${ }^{2}$ Interestingly, $\mathrm{CB}$ experienced no loss of 1,4 unsaturation at $230^{\circ} \mathrm{C}$, in common with $\mathrm{PBD}^{5}$ and with $\mathrm{DI}$ at that same temperature. However, as indicated in Figure 1, loss of 1,4 unsaturation does occur on heating $\mathrm{CB}$ at temperatures above ca. $275^{\circ} \mathrm{C}$.

Figure 6 shows that loss of 1,2 unsaturation in EB and DI follows second-order kinetics, as was the case for $\mathrm{VB}^{1}$; similar plots were obtained for FI but are not displayed here. From the slopes of these straight-line plots (which equal rate constants for various temperatures), three nearly parallel Arrhenius plots were obtained for DI, FI, and EB (Fig. 7), with an average $E_{a}=34.0 \pm 3 \mathrm{kcal} / \mathrm{mole}$; this value is practically the same as that for $\operatorname{VB}\left(E_{a}=33.6 \pm 3 \mathrm{kcal} / \mathrm{mole}\right){ }^{1}$ It thus appears that there is a common mechanism for loss of 1,2 double bonds in 


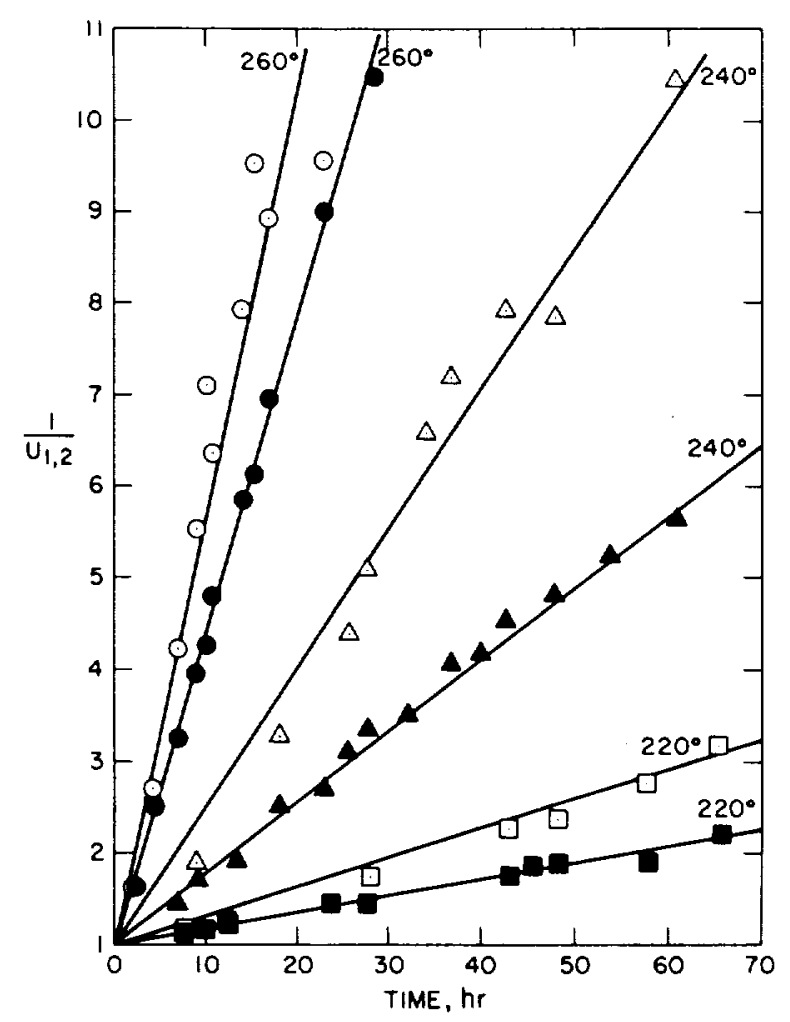

Fig. 6. Typical second-order kinetic plots for loss of 1,2 unsaturation in DI (open symbols) and $\mathrm{EB}$ (closed symbols) films on heating in vacuum at several temperatures.

these four polybutadienes, despite their widely different vinyl contents (10-98\%). The loss of vinyl double bonds in $\mathrm{CB}$ (with $2 \% 1,2$ ), which approximates a second-order process at lower temperatures, was complicated by the formation of new vinyl groups through chain rupture at temperatures above ca. $250^{\circ} \mathrm{C}$. Hence, the $E_{a}$ value for loss of 1,2 double bonds in $\mathrm{CB}$ could not be determined.

It is important to note that treating the loss of 1,2 double bonds in DI as a first-order process (as was done by Grassie and Heaney for $\mathrm{PBD}^{5}$ ), and using the initial slopes of the kinetic plots to obtain an Arrhenius plot, gave essentially the same $E_{a}$ value of ca. $34 \mathrm{kcal} / \mathrm{mole}$ as in the above second-order approach. Hence, the difference in $E_{a}$ values for $\mathrm{PBD}^{5}$ and DI is not a result of assuming different orders for loss of 1,2 double bonds in the two studies, but is probably also a result of the fact that the reaction in $\mathrm{PBD}$ was followed by the ratio $A_{11.1} / A_{10.3}$ instead of by the ratio $A_{11.1} / A_{6.9}$.

Figure 8 shows that the thermally induced loss of 1,4 unsaturation in EB and FI also can be expressed by second-order kinetic plots. From the slopes of such plots, Arrhenius lines were obtained leading to $E_{a}$ values of 35 and $40 \mathrm{kcal} / \mathrm{mole}$ for $\mathrm{EB}$ and FI, respectively. As noted above, DI behaves like $\mathrm{CB}^{2}$ in showing some loss of 1,4 unsaturation above ca. $260^{\circ} \mathrm{C}$ and negligible loss below; consequently, $E_{a}$ values for this reaction could not be obtained for DI or CB.

That methyl production is closely linked to the loss of 1,2 double bonds in the 


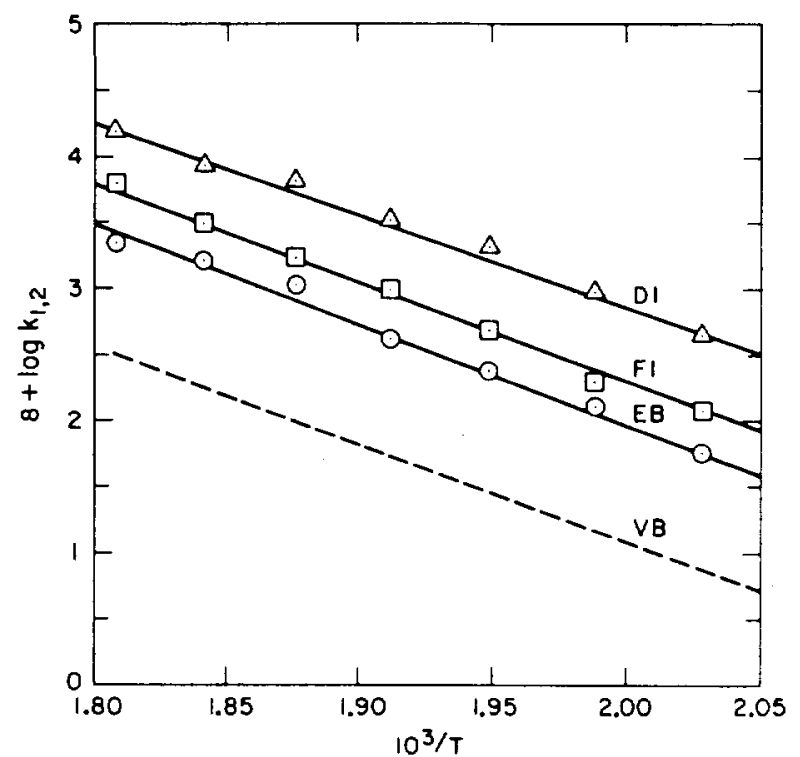

Fig. 7. Arrhenius plots for thermally induced loss of 1,2 unsaturation in DI, FI, and EB. The dashed line is the corresponding plot for VB obtained from ref. 1 .

various polybutadienes examined here may be inferred from Figure 9. The abscissa represents a common-denominator measure of the loss of vinyl units which has the values of $0.48,0.30,0.10$, and 0.02 for complete consumption of 1,2 double bonds in EB, FI, DI, and $\mathrm{CB}$, respectively. The $6.9-\mu \mathrm{m}$ band, used

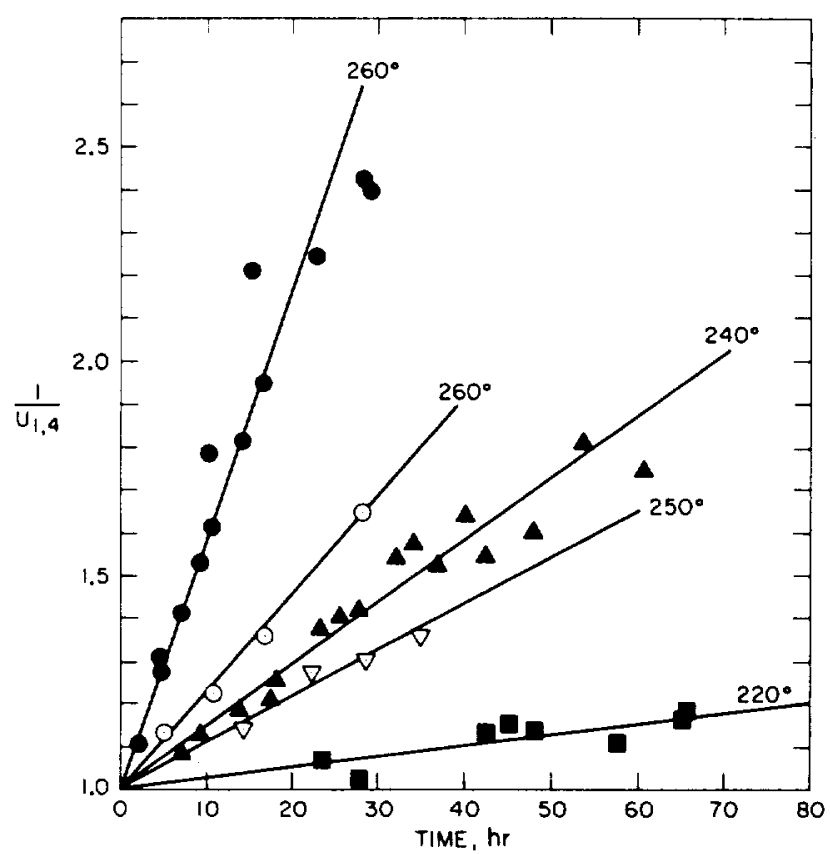

Fig. 8. Second-order kinetic plots for loss of 1,4 unsaturation in FI (open symbols) and EB (closed symbols) films on heating in vacuum at several temperatures. 


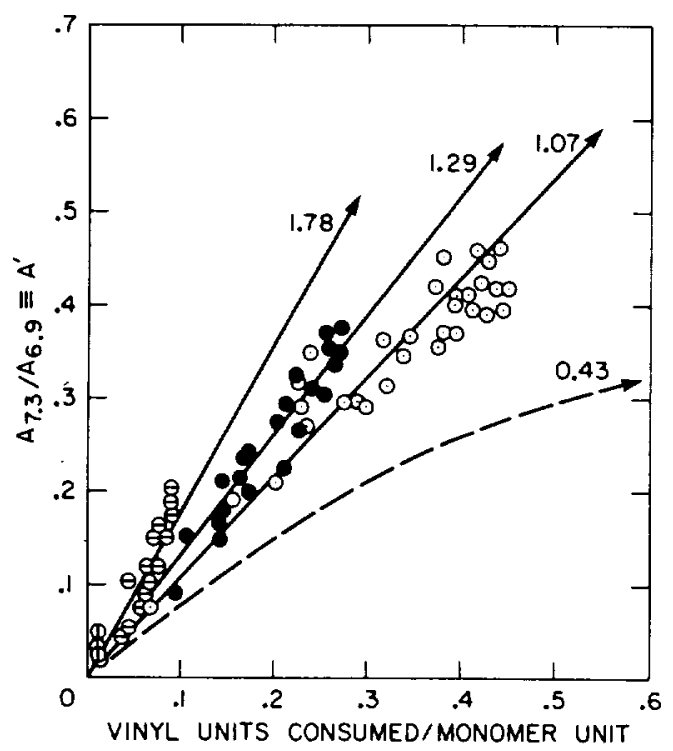

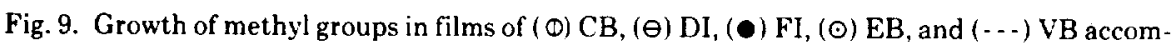
panying loss of 1,2 unsaturation.

to determine $A^{\prime}$, is admittedly not a suitable internal standard for VB at low degrees of reaction, but it is satisfactory for the other polymers. As a test for this, the values for the quantity $\left(A_{11.1} / A_{6.9}\right)_{0} /(\% 1,2)_{0}$ for the unreacted $\mathrm{EB}, \mathrm{FI}$, $\mathrm{DI}$, and $\mathrm{CB}$ are within $5 \%$ of each other. The numbers associated with the straight lines for those polybutadienes (Fig. 9) represent extrapolated values for $A^{\prime}$ corresponding to the hypothetical loss of one vinyl group per monomer unit. The extrapolated value $A^{\prime}=0.43$ associated with the dashed line (for VB) was obtained from Figure 8, ref. 3, representing the formation of methyl groups in the thermal and photochemical cyclization of VB. Now, $A^{\prime}$ is ca. 0.97 for cationically cyclized $\mathrm{VB}^{3}$ which has approximately one methyl group for every two vinyl double bonds reacted in a predominantly monocyclic structure. Thus, $A^{\prime}$ $=1.07$ for EB implies that in this polymer somewhat more than one methyl is formed for every two vinyls consumed; at the other extreme, $A^{\prime}=1.78$ implies that almost every vinyl double bond consumed in DI or CB results in a methyl group. In VB, on the other hand, about one methyl is formed for every four to five vinyls consumed. These surprising results concerning methyl production in the heated polybutadienes make it evident that reactions (1) and (2) cannot be the sole routes to loss of 1,2 double bonds in EB or FI. Instead, processes such as reaction (4)

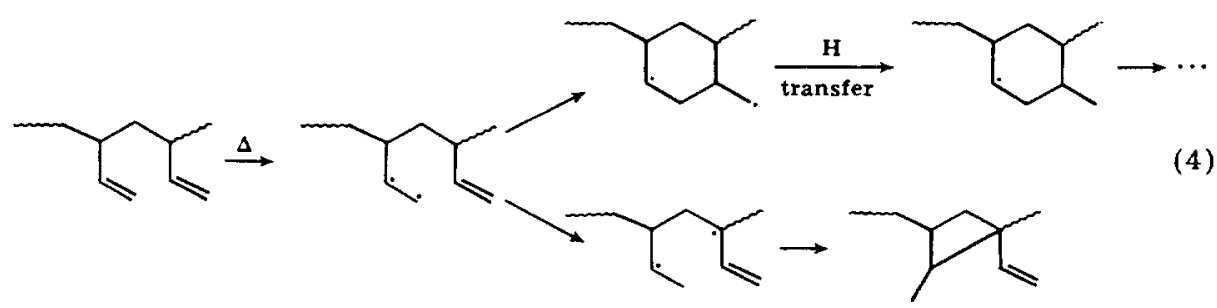


must also be involved. ${ }^{3}$ For the same reason, reaction (3) is not important in $\mathrm{DI}$ (or $\mathrm{PBD}$ ) or $\mathrm{CB}$, but a variation of the Grassie-Heaney reaction yielding methyl groups (as well as crosslinks) is plausible:

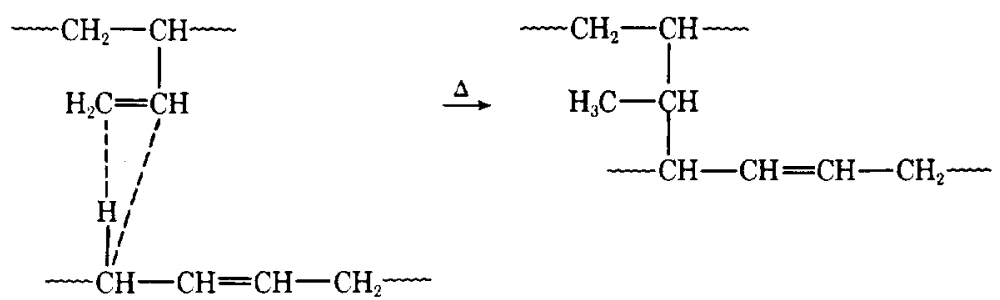

Since the various vinyl-containing polybutadienes studied here were crosslinked on extended heating, as was observed for PBI), ${ }^{5}$ we may invoke reaction (5) and the intermolecular analogs of reactions (1), (2), and/or (4) to account for the thermally induced crosslinking in those polymers. Because of that crosslinking, it was not possible to use NMR spectroscopy to obtain supplemental microstructural information on the thermally rearranged polybutadienes.

Unfortunately, we are not able to be more precise about the thermal reactions leading to loss of 1,2 or 1,4 double bonds in the various polybutadienes. However, it is probable that they are consumed through cycloaddition as well as other processes, some of which yield methyl and some do not. Nor are we able to account for the second-order nature of the loss of 1,4 and/or 1,2 unsaturation in FI, DI, or CB. In the case of VB, or even EB, where $1,2-1,2$ and $1-1,4$ cycloaddition processes appear to be favored, ${ }^{3}$ second-order kinetics for loss of unsaturation is understandable.

In summary, this work has shown that polybutadienes with different vinyl contents undergo facile thermal anaerobic loss of 1,2 double bonds under nonpyrolytic conditions, with activation energies about $34 \mathrm{kcal} / \mathrm{mole}$. Accompanying the loss of 1,2 unsaturation is an important methyl production, ranging from one methyl per vinyl lost in polybutadienes with low vinyl content $(2-10 \%)$ to one methyl per four to five vinyls lost for a high-1,2-polybutadiene. Moreover, polybutadienes with substantial amounts of both 1,2 and 1,4 double bonds also exhibit loss of 1,4 units, presumably through cycloaddition of 1,2-1,4 dyads. Finally, reaction (5) is proposed as an alternative to the Grassie-Heaney reaction for loss of 1,2 double bonds in polybutadienes with relatively low vinyl content.

The author thanks Robert D. Cormia for experimental assistance.

Note added in proof: An attractive alternative to reaction (5) which can account for the loss of vinyls and the accompanying formation of methyls, with no apparent loss of vinylenes, in polybutadienes with low vinyl contents, is reaction (6).

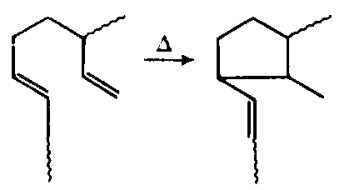

This reaction, which is analogous to the type III (or ene) cyclization, ${ }^{4}$ is supported by the thermal cyclization of 3 -methyl-1,6-nonadiene to cyclopentane-containing structures. ${ }^{\text {? }}$ 


\section{References}

1. M. A. Golub, J. Polym. Sci. Polym. Lett. Ed., 12,615 (1974).

2. M. A. Golub, J. Polym. Sci. Polym. Lett. Ed., 12, 295 (1974).

3. M. A. Golub and M. L. Rosenberg, J. Polym. Sci. Polym. Chem. Ed., 18, 2543 (1980).

4. M. A. Golub, Rubber Chem. Technol, 51, 677 (1978).

5. N. Grassie and A. Heaney, J. Polym. Sci. Polym. Lett. Ed., 12, 89 (1974).

6. R. V. Gemmer and M. A. Golub, J. Polym. Sci. Polym. Chem. Ed., 16, 2985 (1978).

7. M. Santoso, Ph.D. Thesis, University of Maryland, 1978; Diss. Abstr. Int. B, 39, 4383 (1979).

Received July 28,1980

Accepted August 28, 1980 